\title{
Validating the reliability of passive acoustic localisation: a novel method for encountering rare and remote Antarctic blue whales
}

\author{
Brian S. Miller ${ }^{1, *}$, Jay Barlow ${ }^{2}$, Susannah Calderan ${ }^{1}, K_{\text {Ky }}$ Collins ${ }^{1}$, Russell Leaper $^{3}$, \\ Paula Olson ${ }^{2}$, Paul Ensor ${ }^{1}$, David Peel ${ }^{4}$, David Donnelly ${ }^{5}$, Virginia Andrews-Goff ${ }^{1}$, \\ Carlos Olavarria ${ }^{1}$, Kylie Owen ${ }^{6}$, Melinda Rekdahl ${ }^{1}$, Natalie Schmitt ${ }^{1}$, \\ Victoria Wadley ${ }^{1}$, Jason Gedamke ${ }^{7}$, Nick Gales ${ }^{1}$, Michael C. Double ${ }^{1}$ \\ ${ }^{1}$ Australian Marine Mammal Centre, Australian Antarctic Division, Hobart, TAS 7050, Australia \\ ${ }^{2}$ Southwest Fisheries Science Center NMFS/NOAA, 8901 La Jolla Shores Drive, La Jolla, CA 92037, USA \\ ${ }^{3}$ School of Biological Sciences, University of Aberdeen, Tillydrone Avenue, Aberdeen AB24 2TZ, UK \\ ${ }^{4}$ CSIRO Computational Informatics, and Wealth from Oceans National Research Flagship, Castray Esplanade, Hobart, \\ TAS 7000, Australia \\ ${ }^{5}$ Australian Orca Database, Melbourne, VIC 3128, Australia \\ ${ }^{6}$ Cetacean Ecology and Acoustics Laboratory, School of Veterinary Science, The University of Queensland, Gatton, \\ QLD 4343, Australia
}

${ }^{7}$ Ocean Acoustics Program, NOAA Fisheries Office of Science \& Technology, National Oceanic and Atmospheric Administration, Silver Spring, MD 20910, USA

\begin{abstract}
Since its near extirpation during the period of industrial whaling in the early and mid 20th century, the once common Antarctic blue whale Balaenoptera musculus intermedia remains extremely rare. While annual systematic surveys around Antarctica from 1978 to 2009 recorded only 216 visual encounters of this species, their loud and distinctive calls were detected frequently throughout the Southern Ocean. We describe and assess a new method for locating these whales by acoustically detecting their vocalisations, tracking the location of their calls, and finally locating the whales visually. This methodology was employed during an Antarctic research voyage from $140^{\circ} \mathrm{E}$ to $170^{\circ} \mathrm{W}$, between January and March 2013. The loudest song unit (a $26 \mathrm{~Hz}$ tone) was detected at all 298 recording sites south of $52^{\circ} \mathrm{S}$. Acoustically derived bearings from these whales enabled visual observers to eventually sight the whales, often hundreds of kilometres from initial acoustic detections. Received sound pressure levels of detections increased with decreasing range to several hotspots where both song and non-song calls were detected. Within hotspots, shortrange acoustic localisation yielded 33 visual encounters of Antarctic blue whales (group size: 1 to 5 whales) over a $31 \mathrm{~d}$ period south of $60^{\circ} \mathrm{S}$. These results demonstrate that acoustic tracking provides the capacity to locate Antarctic blue whales widely dispersed over many hundreds of kilometres, as well as the capacity to acoustically track individual whales for days at a time irrespective of most weather conditions. Thus, passive acoustic localisation is a reliable and efficient method to track Antarctic blue whales, and this technique should be considered for future studies of these iconic animals.
\end{abstract}

KEY WORDS: Blue whale $\cdot$ Passive acoustics $\cdot$ Tracking

\section{INTRODUCTION}

Antarctic blue whales Balaenoptera musculus intermedia were almost extirpated by the industrial whal-

${ }^{*}$ Corresponding author: brian.miller@aad.gov.au ing that reduced the population to $<1 \%$ of its estimated pre-whaling abundance by 1962 (Branch et al. 2004). While the highest densities of Antarctic blue whales may now be found near the edge of the sea-

(C) The authors 2015. Open Access under Creative Commons by Attribution Licence. Use, distribution and reproduction are unrestricted. Authors and original publication must be credited. 
ice in the Antarctic during the austral summer (Branch et al. 2007), the remoteness of this location, low population size, hostility of the Southern Ocean, and high logistical costs allow for few opportunities to study these whales. Thus, any contemporary assessment of the behaviour, distribution, abundance, and presumed recovery of these iconic whales faces significant challenges.

For 32 yr the International Whaling Commission (IWC) International Decade of Cetacean Research and subsequent Southern Ocean Whale and Ecosystem Research (IDCR-SOWER) programs conducted annual, multi-vessel visual sighting surveys around Antarctica. While a major goal of these surveys was estimating the abundance of minke whales Balaenoptera bonaerensis (Matsuoka et al. 2003), the program also recorded a total of 216 encounters with Antarctic blue whales over 32 yr (4112 vessel-days; 216000 nautical miles [nmi] of transect lines). This low encounter rate yielded 3, somewhat imprecise, abundance estimates for Antarctic blue whales of 453 (coefficient of variation [CV]: 0.40) for 1981, 559 (CV: 0.47 ) for 1988, and 2280 (CV: 0.36) for 1998, with an average annual population growth rate of $8.2 \%$ (95\% confidence interval: 1.6 to $14.8 \%$; Branch 2007).

The IDCR-SOWER program ceased in 2010, and, due to increasing costs, it appears unlikely that a similar survey program will be carried out again. Resources for Antarctic research are diminishing, yet there is the continuing improvement of methods to monitor cetaceans and a strong desire for whale population data from many sources, including the IWC (Anonymous 2010), Antarctic resource managers (CCAMLR; Anonymous 2009a, Lavery et al. 2014) and the wider public. In light of this, the IWC Southern Ocean Research Partnership (IWC-SORP) commenced the Antarctic Blue Whale Project (ABWP) in 2009 (Anonymous 2009b). A goal of this project is to develop and test new field-based and analytical methods that could yield a practical, cost-effective, long-term approach to monitoring Antarctic blue whales (Hammond et al. 2013).

Real-time passive acoustic detection and localisation of marine mammals has seen increased adoption in recent years (Van Parijs et al. 2009), and now comprises some of the most efficient means of locating some marine mammals for the purposes of further study (e.g. Wade et al. 2006, 2011, Clark et al. 2010, Klinck et al. 2012, Rone et al. 2012, Baumgartner et al. 2013). Real-time acoustic detection can be used along with adaptive survey designs in order to increase the amount of time spent with animals during studies that rely on visual observations and/or contact with animals (e.g. Barlow \& Taylor 2005, Baumgartner et al. 2013), or it can comprise the primary means of locating cryptic or critically endangered animals that may be dispersed over large or rarely accessed areas (e.g. Wade et al. 2006, 2011, Klinck et al. 2012, Rone et al. 2012).

Post-voyage (i.e. not real-time) analysis of passive acoustic data collected during the IDCR-SOWER surveys found that Antarctic blue whales sing loud, lowfrequency (i.e. below $100 \mathrm{~Hz}$ ) songs that are distinctive from those of other populations of blue whales (Rankin et al. 2005, McDonald et al. 2006; Fig. 1). Several studies have since reported detections of such blue whale songs in the Antarctic throughout the austral summer, with an apparent circumpolar distribution (Gedamke et al. 2007, Širovi et al. 2009, Samaran et al. 2013, K. M. Stafford et al. unpubl.) and with occasional acoustic detections in the tropics in the austral winter (Stafford et al. 2004, Samaran et al. 2013). Studies have also revealed that individual calls can be localised from distances of 100 to $200 \mathrm{~km}$ (Širovi et al. 2007, Samaran et al. 2010a), and that the songs of blue whales change but remain recognizable over time scales of at least 50 yr (McDonald et al. 2009, Miller et al. 2014). The prolific, distinctive, and stable nature of the song of blue whales suggests that it would be a good candidate for realtime passive acoustic tracking.

While blue whale song is thought to be produced only by males (McDonald et al. 2001, Oleson et al. $2007 \mathrm{~b})$, frequency-modulated 'D' calls are produced

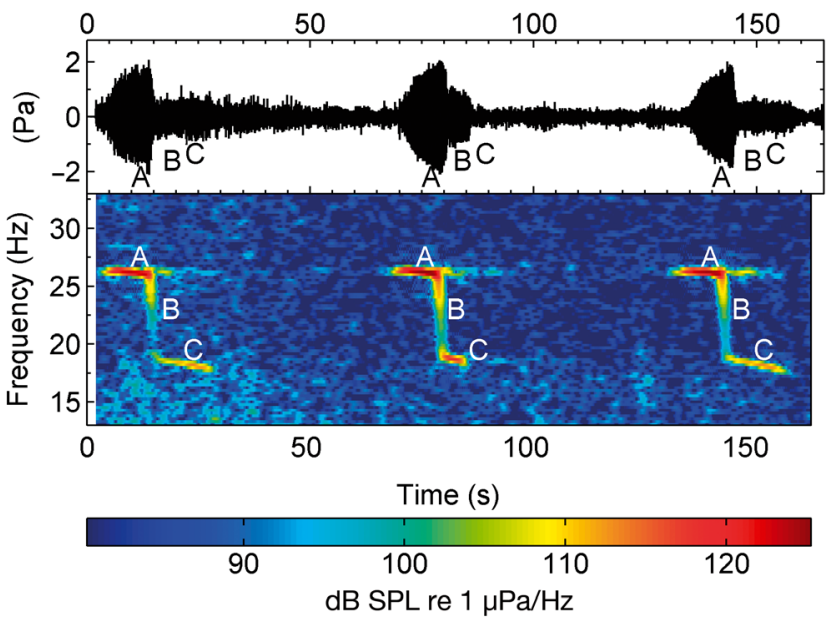

Fig. 1. Pressure waveform (upper panel) and spectrogram (lower panel) of the stereotyped vocalisation made by Antarctic blue whales recorded on 8 February 2013. This 3part call (Units A, B, and C) is referred to as a ' $\mathrm{Z}$ ' call based on the characteristic shape of the call when viewed as a spectrogram. Spectrogram parameters: $250 \mathrm{~Hz}$ sample rate, 1024 point Fast Fourier Transform, 87.5\% overlap between time slices. SPL: sound pressure level 
by both sexes and have been recorded in many populations/locations, including the Antarctic (Rankin et al. 2005, Gedamke \& Robinson 2010). Unlike song, ' $\mathrm{D}$ ' calls are neither stereotyped in their form, nor repeated at regular intervals and may be associated with group (McDonald et al. 2001) and foraging behaviour (Oleson et al. 2007b).

In order to build on the passive acoustic monitoring conducted during IDCR-SOWER (Rankin et al. 2005), the preliminary evidence indicating a long-range (>100 nmi) ability to acoustically detect, track, and approach blue whales during the 2010 Antarctic Whale Expedition (Gales 2010), and an extensive pilot study focused on pygmy blue whales Balaenoptera musculus brevicauda off south-eastern Australia in 2012 (Miller 2012), the Australian Antarctic Division conducted an Antarctic voyage in 2013 focused on Antarctic blue whales. Specifically, the aim of this voyage was to test whether the frequent and long-distance detections of blue whale song could be used to reliably and efficiently visually locate Antarctic blue whales on their summer feeding grounds, which would then facilitate behavioural observations, photographic identification, and genetic sampling of this seldom encountered subspecies.

\section{MATERIALS AND METHODS}

The FV 'Amaltal Explorer' departed from Nelson, New Zealand, on 30 January 2013 to operate near Antarctic sea-ice within a predefined study area $\left(140^{\circ} \mathrm{E}\right.$ to $170^{\circ} \mathrm{W}$; Fig. 2). This study area was chosen based on the endurance of the vessel, its home port and previous IDCRSOWER sightings and acoustic detections from the area. Visual surveys were conducted during daylight hours by observers on the open-air flying bridge (eye height: $10 \mathrm{~m}$ ), or in the enclosed bridge (eye height: $7.9 \mathrm{~m}$ ) when wind speeds were $>25$ knots. Unlike many combined acoustic and visual surveys for marine mammals, communication between the visual observers and acoustics team was not only encouraged, but also a requirement for real-time acoustic tracking. The voyage science plan (Double 2013) provides a detailed description of all protocols employed on the voyage.

\section{Acoustic protocols at sea}

A team of 5 dedicated acousticians monitored round-the-clock for blue whales and in all weather conditions. The underlying technology and general principles of the acoustic tracking system were identical to the pilot study in southeast Australian waters (Miller et al. 2012). DIFAR (directional frequency analysis and recording) sonobuoys formed the primary means of passive acoustic monitoring.

Sonobuoys sent acoustic and directional data to the ship via a VHF radio transmitter. Radio signals from the sonobuoy were received using an omnidirectional VHF antenna (PCTel MFB1443; 3 dB gain tuned to

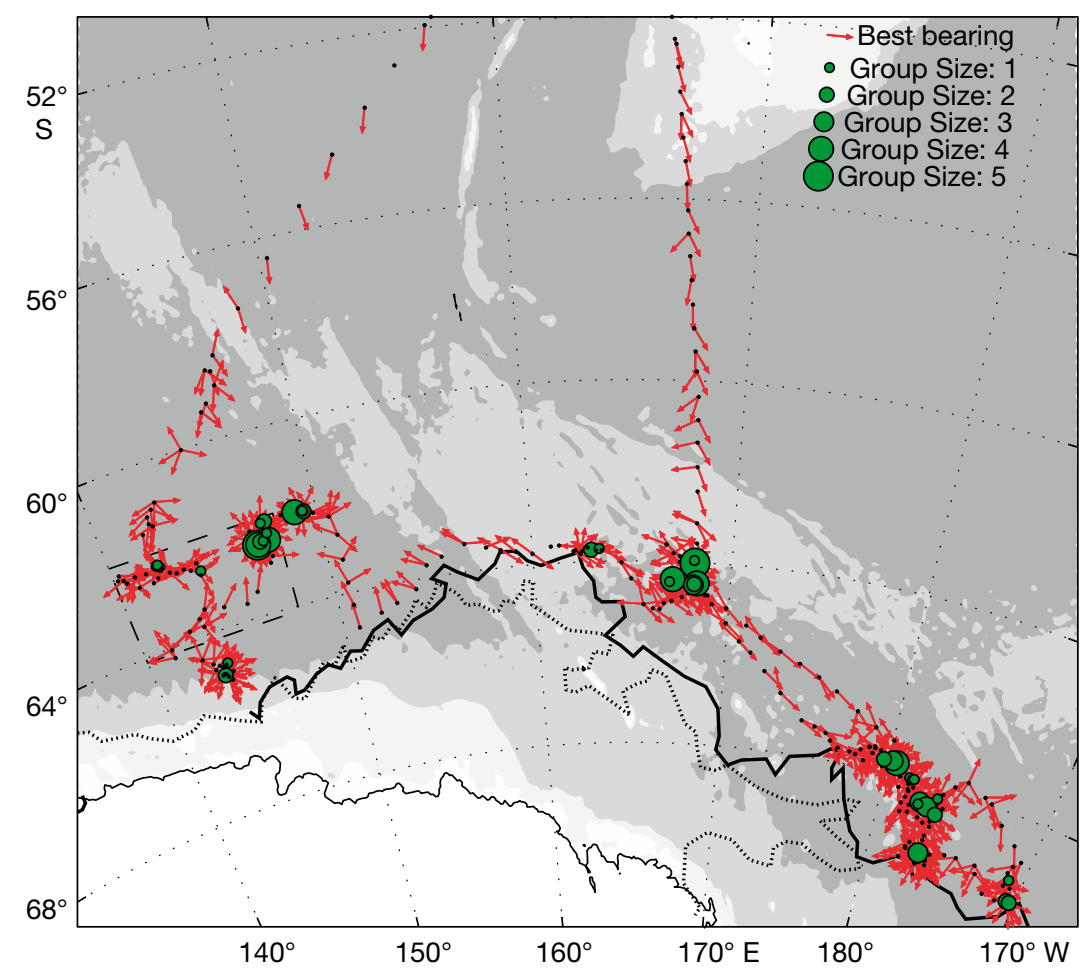

Fig. 2. Visual and acoustic locations of Antarctic blue whales during the 2013 voyage (including transit). Black dots show location of listening stations, while red arrows indicate best bearings to vocalisations from Antarctic blue whales (i.e. the peaks of the bearing-density function). Visual sightings of blue whales are indicated by green circles, with group size indicated by circle diameter. Real-time acoustic data from the area within the outlined rectangle are shown in detail in Fig. 3. Gray shading indicates the 200, 3000, and $6000 \mathrm{~m}$ depth contours, respectively, from light to dark. Solid and dashed bold black lines show the maximum and minimum extents of the ice-edge as determined by AMSR2 sea-ice images (www.iup.uni-bremen.de:8084/amsr2/) 
$144 \mathrm{MHz}$ centre frequency) and pre-amplifier (Minicircuits ZX60-33LN-S+) mounted on the mast of the ship at a height of $21 \mathrm{~m}$. The pre-amplifier was connected to a power splitter via LMR400 cable, and signals were received with 2 WiNRaDiO G39WSBe sonobuoy receivers. The radio signal from sonobuoys was adequate for monitoring and localisation out to a typical range of 12 to $15 \mathrm{nmi}$. Received signals were digitised via a sound board (Fireface UFX, RME), and signals were recorded on a personal computer using the software program PAMGuard (Gillespie et al. 2008). Three models of sonobuoys were used during the voyage: 79 were AN/SSQ-53D (Ultra Electronics), 81 were AN/SSQ-53F (Ultra Electronics: Sonobuoy TechSystems), and 200 were AN/SSQ-955-HIDAR equipment (deployed in DIFAR compatibility mode; Ultra Electronics Sonar Systems).

During the $47 \mathrm{~d}$ voyage 360 sonobuoys were deployed yielding $733 \mathrm{~h}$ of acoustic recordings. On average, slightly more than 8 sonobuoys were used per survey day. A total of 93 sonobuoys were deployed in transit to or from the edge of the sea-ice, while the remainder were deployed to 'monitor' and 'target' Antarctic blue whales. The telemetered audio from sonobuoys was monitored aurally and visually (via spectrogram) in real-time by one or more onduty acousticians. Upon detection of blue whale vocalisations the vessel was directed towards the locations of these sounds.

There were multiple acoustic survey modes with 2 main modes of monitoring and targeting. During monitoring, sonobuoys were deployed at $30 \mathrm{nmi}$ intervals to balance the desire for frequent, systematic recording stations with the finite number of sonobuoys available during the voyage. Groups of bearings that appeared to come from the same direction and had regular repetition rates were monitored as a group of whales that were then given a unique designation. Monitored groups of whales that we attempted to approach were considered target whales.

Of the monitored groups of whales, only a limited number were selected as good candidates for targeting based on consistency of vocalising behaviour, proximity, and logistical considerations (e.g. weather and sea-ice forecasts). Proximity was estimated from the rate of change of intensities and bearings of acoustic detections (i.e. higher rates of change were believed to be closer). Targets were considered 'aborted' when the target could still be monitored, but operational or environmental constraints prevented an approach to the whale. Targets were considered 'missed' when the target did not yield a visual encounter with blue whales and could no longer be monitored. During targeting, sonobuoys were deployed adaptively as needed.

There were 3 main sub-modes of targeting: longrange, short-range, and overnight. Long-range targeting involved deploying single sonobuoys at $30 \mathrm{nmi}$ intervals and following an acoustic bearing towards a target group that was believed to be further than $30 \mathrm{nmi}$ away. Short-range targeting mode involved adaptively deploying additional sonobuoys as needed in order to close in on individual vocalising whales believed to be within $30 \mathrm{nmi}$ of the vessel. Overnight targeting involved deploying sonobuoys to maintain an acoustic track of vocalising whales in order to position the ship within visual sighting range of blue whales by dawn when photoidentification and biopsy effort could resume. In principle, overnight targeting was identical to long- or short-range targeting; however, in the vicinity of sea-ice, vessel speed overnight was often limited to $3-5$ knots. Fig. 3 shows an example of a period of $48 \mathrm{~h}$ of acoustic tracking that contains most of the different acoustic survey modes: monitoring, as well as long-range, short-range, and overnight targeting.

The 2 main strategies for short-range and overnight targeting were (1) to deploy multiple sonobuoys to triangulate the position of a calling whale and/or (2) to closely follow a bearing from a sonobuoy that was believed to be deployed $<10 \mathrm{nmi}$ from a whale. During short-range targeting, it was necessary to deploy sonobuoys more frequently, with typical spacing of $12 \mathrm{nmi}$ during a bearing search, and 8 to $12 \mathrm{nmi}$ for obtaining cross bearings. When deploying a second sonobuoy for the purpose of triangulation, a course of 30 to $60^{\circ}$ relative to the bearing from the first sonobuoy to the target was often selected in order to facilitate triangulation (i.e. Nardone \& Aidala 1981) while continuing to reduce the distance between the vessel and the target.

The final mode of operation, short-range monitoring, occurred when the vessel was with whales or in a close approach. During short-range monitoring sonobuoys were deployed opportunistically to maintain an acoustic track of whales during sighting, photography, and biopsy attempts.

\section{At-sea analysis of calls}

Calls were classified subjectively based on their appearance in the spectrogram (spectral resolution of approximately $0.5 \mathrm{~Hz}$, time-slice of approximately $2 \mathrm{~s}$, $95 \%$ overlap). Calls comprising the full Antarctic blue whale song were further classified as either $26 \mathrm{~Hz}$ 


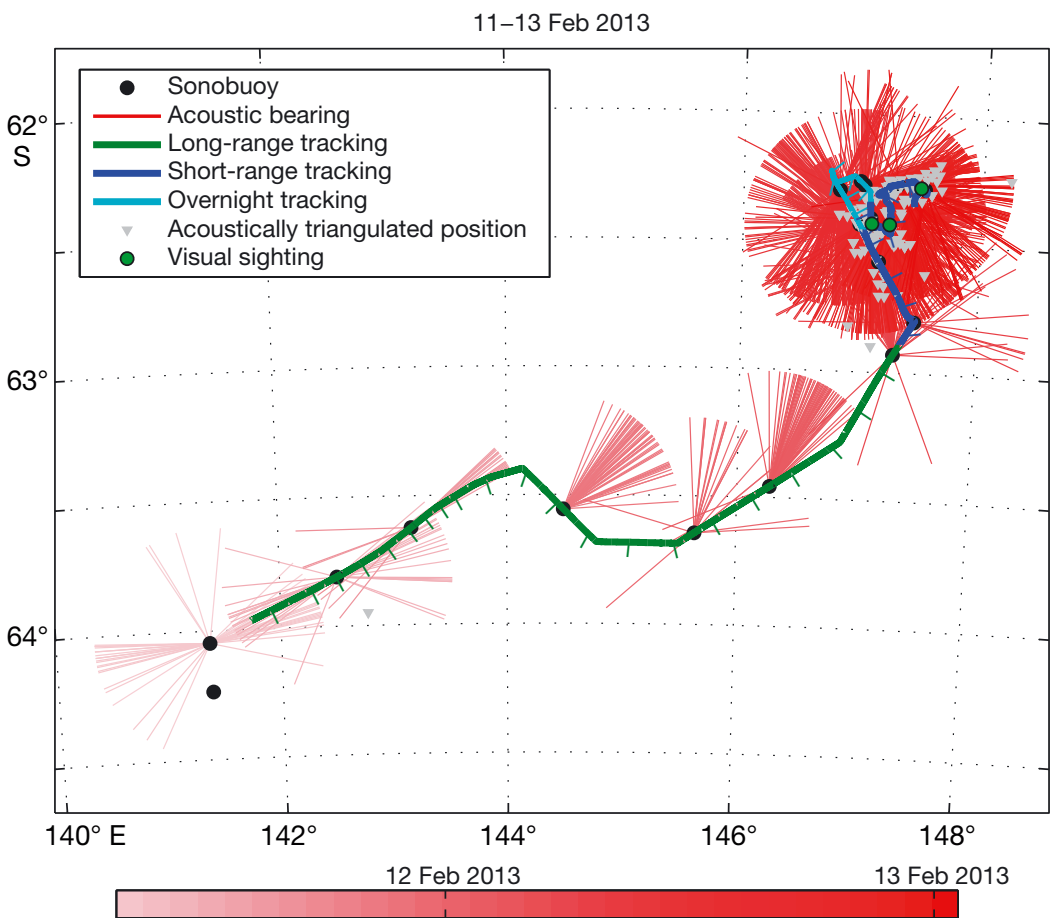

Fig. 3. Various types of acoustic survey modes over a $48 \mathrm{~h}$ period. Green, blue, and cyan lines show the ship's track during long-range, short-range, and overnight targeting, respectively, with tick marks at $1 \mathrm{~h}$ intervals. Black circles show the locations of sonobuoys. Red lines show bearings to individual whale calls, with lighter colours indicative of older bearings. During initial monitoring, in the southwest, at least 3 clusters of bearing angles were evident. The cluster of bearings in the northeast sweeps over a full $360^{\circ}$ : a typical result when deploying buoys in close proximity to a group of whales. Grey triangles show whale positions triangulated acoustically; green circles indicate visual sightings of blue whales

tones or ' $\mathrm{Z}$ ' calls. The $26 \mathrm{~Hz}$ tones are an evolution from the $28 \mathrm{~Hz}$ tones described by others (e.g. Rankin et al. 2005), which have been gradually decreasing in frequency (McDonald et al. 2009, Gavrilov et al. 2012). Each 'Z' call, named for its characteristic shape when viewed as a spectrogram, was composed of 3 units that we labelled A, B, and C (Fig. 1) following the convention of Cummings \& Thompson (1971). The $26 \mathrm{~Hz}$ tone was essentially the same as Unit A, but without subsequent detection of Units B or C. Frequency-modulated calls $>2 \mathrm{~s}$ in duration were subjectively classified as ' $\mathrm{D}$ ' calls of blue whales, depending on the shape of the call (i.e. duration, sweep rate, concavity) and context (i.e. occurrence and classification of preceding and/or following calls).

Analysis of the bearings to sound sources followed the methods of Miller et al. (2012, 2013, 2014). This involved a series of signal-processing steps on saved audio clips performed via a suite of MATLAB scripts. Signal processing included the 'validation' of the sonobuoy compass and measurement of a compass correction for each sonobuoy as described in Miller et al. (2012, 2013, 2014). The final output was a true bearing from the sonobuoy to the sound source of interest.

\section{Post-voyage analysis}

The number of groups monitored, number of groups tracked, and the encounter rate (i.e. number of visual observations) were calculated from the original voyage logs (i.e. no post hoc analyses of the raw acoustic waveforms were conducted). To obtain summaries of the directional data, kernel smoothing (Wand \& Jones 1995) was applied to all the bearings of each type of call for each sonobuoy to yield a continuous bearing density function (BDF). Peaks in the BDF (analogous to modes of the circular distribution of bearings) greater than a threshold value were selected as the 'best bearing' to a monitored group. The threshold value was computed per sonobuoy as $1 / 2 \sigma n$, where $\sigma$ represents the angular precision of bearings from the sonobuoy, and $n$ was the total number of bearings for each call type obtained at that sonobuoy. The nominal angular precision of $10^{\circ}$, as specified by the manufacturers, was used as the value of $\sigma$ for all sonobuoys. Best bearings rather than mean bearings were used in order to facilitate differentiation between different monitored groups that were simultaneously detected.

During the Antarctic voyage, the relative change in intensity of a series of monitored calls was used as a measure of distance to the monitored group. To summarise these data, the average root mean square (RMS)-received level in the 25 to $27 \mathrm{~Hz}$ band was calculated from all of the song calls that comprised each of the best bearings. Average levels were computed in linear units (i.e. pressure), and the average pressure was then converted to dB re $1 \mu \mathrm{Pa}$ RMS. Mean RMS-received levels for ' $\mathrm{D}$ ' calls were computed in the 20 to $80 \mathrm{~Hz}$ band, again for each best bearing. However, during the voyage, RMS values from ' $\mathrm{D}$ ' calls were not used for range estimation, since ' $D$ ' calls did not all have the same bandwidth (Rankin et al. 2005) and were also believed to have variable source levels (Gavrilov et al. 2011). 


\section{RESULTS}

\section{Distribution of detections and received levels}

Faint vocalisations from Antarctic blue whales Balaenoptera musculus intermedia were first recorded at $51.95^{\circ} \mathrm{S}, 157.55^{\circ} \mathrm{E}$ (Fig. 2). These detections comprised only a small portion of the call Unit A (Fig. 1). Subsequently, Unit A from the song of Antarctic blue whales was detected on every fully functional sonobuoy deployed south of $52^{\circ} \mathrm{S}$. Received levels of Antarctic blue whale vocalisations increased steadily in conjunction with latitude until approximately $58^{\circ} \mathrm{S}$ (Fig. 4). The direction of Antarctic blue whale vocalisations was predominantly from the south during transits. However, around $57^{\circ} \mathrm{S}$, vocalisations were detected from both the north and south, suggesting a group of vocalising Antarctic blue whales in the vicinity of $57^{\circ} \mathrm{S}$ (Fig. 2). The intensity of calls dropped slightly after passing $58^{\circ} \mathrm{S}$, and further analysis is required to determine whether this was a result of moving away from a northerly group of whales, or an effect of long-range sound propagation (e.g. reflection from the Antarctic circumpolar front) from more southerly groups of whales.

In general, received levels increased with proximity to sightings and decreased further away (Fig. 4). Generally, sightings occurred once mean received levels exceeded $108 \mathrm{~dB}$ re $1 \mu \mathrm{Pa}$ RMS for both song and ' $\mathrm{D}$ ' calls (dashed line in Fig. 4). However, movement of vocalising whales and the intermittent and variable nature of calling behaviour precludes stronger inferences from the time-series of received levels without additional detailed quantitative analysis. During the $31 \mathrm{~d}$ in the vicinity of the ice-edge, $6078 \mathrm{~km}$ of visual survey effort was conducted over $346 \mathrm{~h}$. During this $31 \mathrm{~d}$ period, Unit A of the Antarctic blue whale call (presumably the most intense unit) was detected on all 237 fully functional sonobuoys that were deployed. 'D' calls were detected on nearly

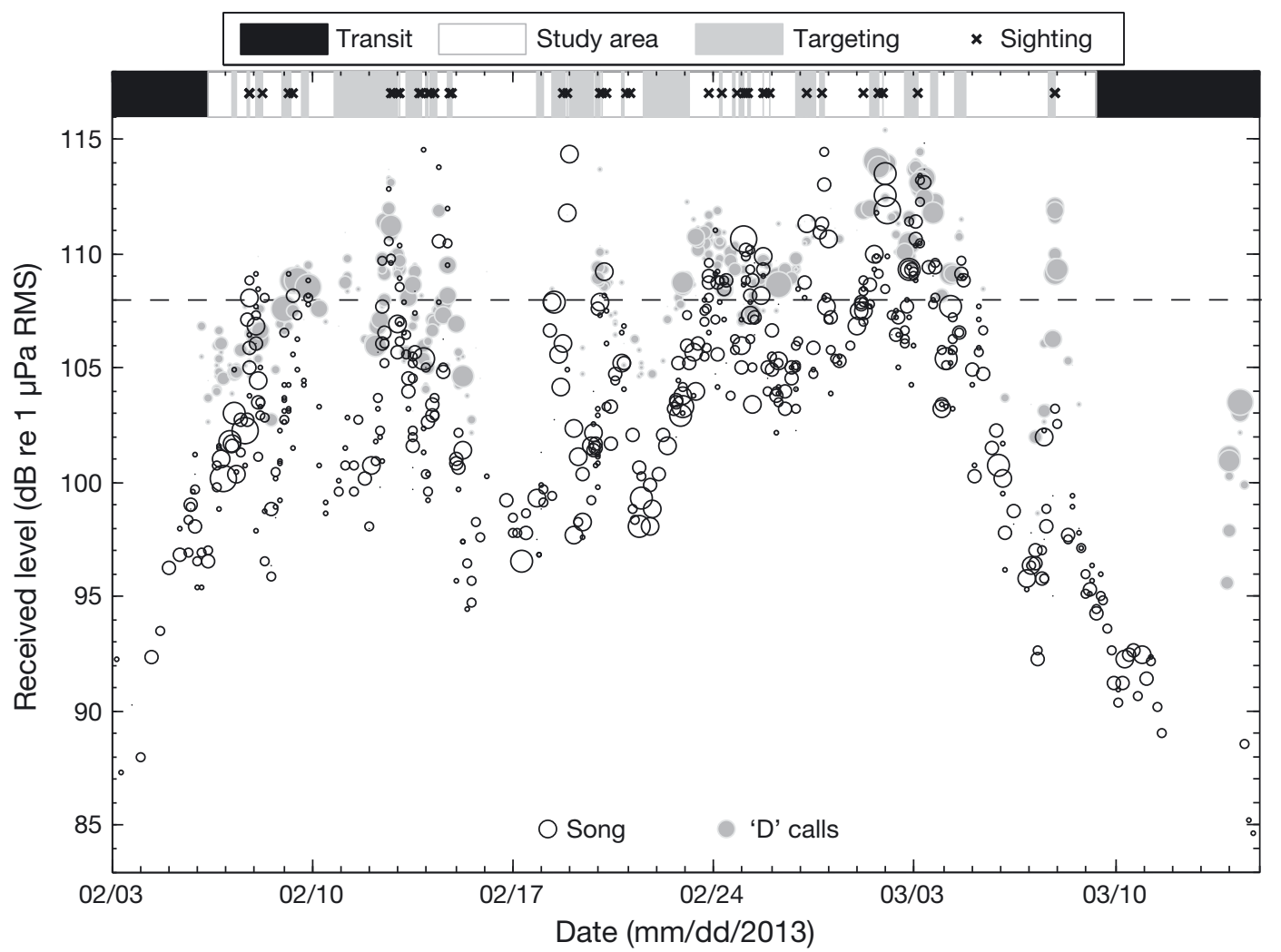

Fig. 4. Received levels of Antarctic blue whale calls detected during monitoring and targeting. The black, white and gray shading in the timeline at the top of the figure indicates the type of acoustic effort at that time, while crosses denote the start time of encounters with groups of Antarctic blue whales. Circles show the mean received levels comprising the best bearing to song calls and ' $\mathrm{D}$ ' calls. The size of each symbol is proportional to the detection rate of calls (i.e. calls $\mathrm{h}^{-1}$ ). While the overall pattern is somewhat complex, mean received levels generally increased while targeting and generally decreased after departing from encounters. The dashed line at $108 \mathrm{~dB}$ was determined by visual inspection of the figure and indicates a threshold for which encounters almost always occurred 
twice as many sonobuoys as entire ' $\mathrm{Z}$ ' calls (i.e. containing Units A, B, and C). Detections of entire ' $\mathrm{Z}$ ' calls and ' $\mathrm{D}$ ' calls appeared to be clustered near locations of encounters with Antarctic blue whales (Fig. 5), while Unit A was audible throughout the area south of $52^{\circ} \mathrm{S}$ (Figs. $2 \& 5$ ).

\section{Targeting}

Fifty-two groups of whales were targeted, which yielded 24 visually confirmed encounters. In addition, 9 attempts yielded encounters with Antarctic blue whales that were not believed to be, but were close to, the targeted vocalising whales, and thus believed to be 'associated' with the acoustically targeted whale (see 'Discussion; Antarctic blue whale hotspots' for further explanation). Searches for 13 of the 52 targets were aborted. Eight targets were aborted in order to target whales that were believed to be closer; 3 targets were aborted due to difficult pack-ice conditions that were not passable; 1 was aborted due to poor weather; and 1 target was aborted to continue the visual survey in a different area. Finally, 6 of the targets were missed because the whale stopped vocalising and could no longer be acoustically located (Table 1).

The 33 visual encounters with an estimated total of 84 Antarctic blue whales allowed for photo-identification of 50 individuals, the collection of 23 biopsies, the deployment of 2 satellite tags (Table 1), and the collection of detailed photogrammetric movement data. All of the visual encounters during the voyage were of whales that were either targeted or associated with targets.

The success rate of acoustic targeting was $63 \%$, computed simply as the number of visually confirmed targets and acoustic associates divided by the total number of targets (i.e. 33/52). However, it could be argued that because aborted targets yielded indeterminate results, they should not be included when calculating success rate. Exclusion of aborted targets yields a success rate of $85 \%$ (33/39). These 2 rates might, re-

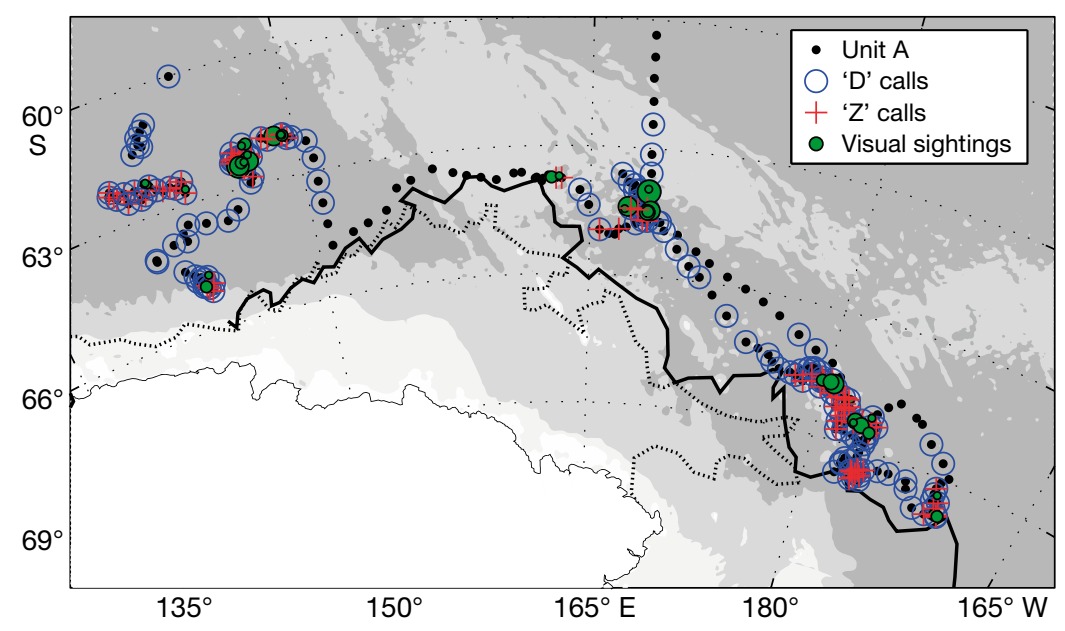

Fig. 5. Detections of Antarctic blue whale vocalisations in the study area. Unit A (i.e. $26 \mathrm{~Hz}$ tone) was detected on every sonobuoy deployed in the study area, while ' $\mathrm{D}$ ' calls, and ' $\mathrm{Z}$ ' calls, were detected only on sonobuoys that were nearer to visual sightings of whales. Gray shading indicates the 200, 3000, and $6000 \mathrm{~m}$ depth contours, respectively, from light to dark. Solid and dashed bold lines show the maximum and minimum extents of the ice-edge as determined by AMSR2 sea-ice images (www.iup.uni-bremen.de:8084/amsr2/)

Table 1. Summary of voyage metrics for Antarctic blue whales (ABWs), including acoustic monitoring, targeting, visual encounters, and samples (identifications, biopsies, and tags)

\begin{tabular}{|lccc|}
\hline Measure & Transit & Ice-edge & Total \\
\hline Sonobuoys deployed & 93 & 268 & 361 \\
Number of failed buoys & 12 & 31 & 43 \\
Audio recorded (h) & 168.6 & 564.4 & 733.0 \\
Audio from 2 simultaneous buoys (\%) & 27 & 58 & 52 \\
ABW song calls analysed in real-time & 794 & 18601 & 19395 \\
'D' calls analysed in real-time (ABW) & 36 & 7603 & 7639 \\
Triangulated locations (ABW real-time) & 0 & 3146 & 3146 \\
Targets pursued & 0 & 52 & 52 \\
Targets successful & 0 & 33 & 33 \\
Targets aborted & 0 & 13 & 13 \\
Targets missed & 0 & 6 & 6 \\
Visual survey hours & 64.1 & 346.6 & 410.7 \\
Distance surveyed (km) & 1229 & 6078 & 9298 \\
Visual encounters & 0 & 33 & 33 \\
Whales sighted & 0 & 84 & 84 \\
Photographic identifications & 0 & 50 & 50 \\
Biopsy samples & 0 & 23 & 23 \\
Satellite location tags & 0 & 2 & 2 \\
\hline
\end{tabular}

spectively, be thought of as indicative of 'typical' and 'best-case' success rates for acoustic targeting.

However, whilst not always explicitly recorded as distinct acoustic targets, there were several occasions when directional information provided by acoustic monitoring rather than targeting contributed to efficient, successful recommencement of visual contact with whale(s) that had been inadvertently lost (due to 
poor sighting conditions, snowstorms, and/or fog). Thus, some discussion of the factors that affected acoustic tracking is warranted.

\section{DISCUSSION}

Real-time acoustic tracking proved to be a reliable and resilient method for locating groups of Antarctic blue whales Balaenoptera musculus intermedia that were widely separated across a large portion of the Southern Ocean. Acoustic tracking of Antarctic blue whales was conducted continuously and successfully throughout the voyage, with no critical failures or long periods of unscheduled down-time. In addition to locating whales for photographic identification and genetic sampling, passive acoustic localisation also yielded insight into the spatial distribution of Antarctic blue whales throughout the survey area. Furthermore, the continuous collection of passive acoustic data provided additional information on the relationship between acoustic detections and sightings of Antarctic blue whales.

\section{Factors that affected acoustic targeting}

\section{Weather}

There was only 1 day where weather and sea state affected acoustic operations, and this only resulted in a delay of a few hours between listening stations. Sonobuoy VHF reception and the signal-to-noise ratio of acoustic recordings were diminished above Beaufort sea state 6 ; yet, even so, the quality of acoustic data at these times remained adequate. Therefore, it was possible to continue acoustic operations under these conditions. Whilst fog and snow seriously impeded visual sighting efficacy, these conditions had minimal effect on acoustics operations. In fact, on several occasions whales that had been visually detected and subsequently lost due to poor sighting conditions were relocated using the acoustic data.

\section{Targeting strategies}

Both following a bearing line as well as obtaining cross bearings proved to be successful strategies for short-range targeting, and it should be noted that these methods were not mutually exclusive. Following bearing lines seemed to facilitate finding whales slightly faster when short-range targeting immedi- ately followed long-range targeting. However, obtaining cross bearings proved to be more useful during overnight targeting as well as close approaches.

In addition to the aforementioned targeting strategies, another key element of a successful scenario was patience. Upon arriving at the location of an acoustic target, environmental conditions such as darkness, fog, snow, or ice sometimes prevented the visual team from being able to detect or sample the acoustically targeted whales immediately. However, given the temporal and spatial scales involved in targeting a new aggregation, staying with a group which had already been acoustically located was often the most sensible option, even if this entailed waiting at the whales' location for many hours. While additional data collection and further studies are required to determine the proportion of time that blue whales spend vocalising, there were a number of occasions, especially overnight, when nearby whales became silent. In these instances, simply staying in the area and monitoring for the next vocalisation proved a successful strategy, as vocalisations invariably resumed, albeit sometimes hours later. The same temporal and spatial scales that make patience a successful strategy for encountering whales also lend support to the idea that the distribution of blue whales is patchy (Gedamke \& Robinson 2010, Peel et al. 2014).

\section{Antarctic blue whale hotspots}

The spatial distribution of the detections of calls from Antarctic blue whales further supports the notion that Antarctic blue whales have a patchy distribution (Gedamke \& Robinson 2010, Peel et al. 2014), at least along the ice-edge from $140^{\circ} \mathrm{E}$ to $170^{\circ} \mathrm{W}$. While call Unit A was detected throughout the study area, the bearings to these vocalisations were indicative of 7 hotspots within the area that contained aggregations of groups of whales, rather than uniformly distributed groups (Fig. 2). The idea of hotspots is further supported by the fact that all visual sightings of Antarctic blue whales were either acoustically targeted whales or believed to be associated with vocalising groups of whales; no blue whales were sighted independently of acoustic targets. Associated whales were believed to be near the acoustically targeted whale; however, estimating these distances was not straightforward due to the fact that (1) distances between targets and associated whales often exceeded the effective range of visual detections and (2) whales were constantly moving with respect to the vessel and each other. 
'D' and ' $\mathrm{Z}$ ' calls were not detected over distances as great as those for Unit A, yet they were always detected at or near encounters with Antarctic blue whales, suggesting that they are excellent indicators of proximity to these hotspots (Fig. 5). The 7 distinct hotspots for Antarctic blue whales were found in the western, central, and south-eastern parts of the area surveyed (Fig. 5). Each of these hotspots was initially detected from distances of $>100 \mathrm{nmi}$ away. Furthermore, the best bearings (Fig. 2) and mean received levels (Fig. 4) suggest that the transits to and from the ice-edge are essentially extreme cases of long-range targeting. In these cases whale vocalisations from the most westerly $\left(62^{\circ} \mathrm{S}, 140^{\circ} \mathrm{E}\right)$ and central hotspots $\left(64^{\circ} \mathrm{S}\right.$, $170^{\circ} \mathrm{E}$ ) were audible from approximately $600 \mathrm{nmi}$ away during the transits, which may represent the largest detection range of any whale species obtained in real-time via civilian facilities (as opposed to networks of military sensors spread across ocean basins, e.g. Stafford et al. 1998). The steady increase in received level of both ' $\mathrm{D}$ ' calls and song when approaching these hotspots (Fig. 4) suggests that acoustic hotspots may persist for several days even if individual whales within the hotspots may change. Thus, targeting of acoustic hotspots even from long distances represents a reliable method for encountering Antarctic blue whales.

While robust determination of the 'actual' acoustic communication space utilized by whales is beyond the scope of this study, our long-range detection and tracking results are at least supportive of the longstanding hypothesis that the communication space of Antarctic whales potentially spans thousands of kilometres (Payne \& Webb 1971). Regardless of the function of these calls, we agree with the basic premise proposed by Payne \& Webb (1971) that the long-distance propagation of these low-frequency calls arises from the combination of high source-levels of Antarctic blue whale calls (Širovi et al. 2007, Samaran et al. 2010b) and low propagation losses within the Antarctic surface duct (Urick 1983, Hall 2005).

\section{Relationship between acoustic detections and sightings}

The close association between hotspots, Antarctic blue whale song, and 'D' calls found during the 2013 voyage provides a complementary viewpoint to the findings of prior visual-acoustic surveys for blue whales. Rankin et al. (2005) found that at least 12 (and possibly up to 14) of 15 groups of Antarctic blue whales that were first encountered by visual means were subsequently found to make ' $\mathrm{Z}$ ' and/or 'D' calls when acoustic monitoring was conducted. Their observation that vocalisations were unambiguously detected for at least $80 \%$ of the groups within a few hours of encounter is consistent with our results.

Oleson et al. (2007a) suggested that the total number of 'D' calls may, at least to some degree, be a reliable indicator of whale density in the vicinity of the hydrophone, but that song was not. However, they suggest that the lack of relationship between received song and local density may have partly arisen from the distances over which songs were detected (Oleson et al. 2007a). The few estimates of the source levels for 'D' calls (Thode et al. 2000, Gavrilov et al. 2011) indicate that the detection range of these calls is likely to be smaller than that of song, but still considerably greater than visual detection ranges. Similar to Oleson et al. (2007a), we found that song appeared, at least qualitatively, to have a larger detection range than 'D' calls (Fig. 5). However, unlike Oleson et al. (2007a) we were under no obligation to follow a track-line, and thus could better explore the relationship between detections of song, location of singers, and the number of whales present.

Also similar to Oleson et al. (2007a), Gedamke \& Robinson (2010) conducted a systematic passive acoustic survey on a cruise with rigidly defined transects and no ability to break from the track-line to search for vocalising whales. During their survey no blue whales were seen by the team of dedicated visual observers, yet Antarctic blue whale song units were detected at nearly a third of the recording sites, and ' $\mathrm{D}$ ' calls were detected at more than one-sixth of the 145 acoustic recording sites. While no whales were sighted, the consistency of bearings to vocalising whales over large distances and long time frames suggested the feasibility of the long-range tracking methodology presented here. In addition, the clustering of acoustic detections, and similarity in bearings to multiple vocalising blue whales were an early indication of the presence of hotspots, at least from acoustic detections alone.

In addition to confirming that passive acoustic tracking is a reliable method for locating Antarctic blue whales, the data from the 2013 voyage also suggest that an acoustically assisted survey is likely to be more efficient than purely visual surveys. Using simulations with parameters very similar to those of the voyage, Peel et al. (2014) estimated a 2- to 3-fold increase in close encounters for an acoustically assisted survey of Antarctic blue whales over that of a purely visual survey. The 33 encounters with Antarctic blue whales during the 2013 Antarctic Blue Whale Voy- 
age was not only within the range of encounters estimated via simulation, but also compares favourably to the combined 38 encounters from the 6 prior IDCR-SOWER visual line-transect surveys conducted in the same area (Branch 2007). Furthermore, the simulation accounted for increased density by assuming a $6.4 \%$ annual population growth rate since the last abundance estimate (Peel et al. 2014). Thus, it is likely that increased encounters in 2013 were due primarily to the use of passive acoustic tracking rather than simply an increase in whale abundance.

\section{Implications for future studies of Antarctic blue and other whales}

The ability to track and target whales over large areas and moderate time scales opens up an array of options for exploring efficient and opportunistic methods of finding Antarctic blue whales. Combined visual and acoustic detection techniques such as conducting a structured, adaptive-sampling visual transect throughout a hotspot while simultaneously tracking vocalising whales may provide even better estimates of group size and spatial extent (i.e. patchiness). Such knowledge could in turn be used to optimise the amount of time spent obtaining biopsy and photographic identification samples for mark-recapture abundance estimation, or could be used to better quantify 'multipliers' for estimation of density via passive acoustics (Thomas \& Marques 2012).

The fact that we were able to track vocalising Antarctic blue whales for days at a time presents additional opportunities for detailed observations of whales within an aggregation. Acoustic tracking of whales provides a means to stay with a group of whales as long as they continue vocalising in order to ensure sampling of as many individuals within a group as possible. Combined with a gradual initial approach, this additional time with whales may allow whales to habituate to the research vessel, facilitate observations of undisturbed behaviour, and mitigate against potential disturbances that may arise from close approach (e.g. Ensor et al. 2006, Double et al. 2013).

Acoustic tracking introduces the ability to study Antarctic blue whales over longer time periods than those required for photographic identification and/or biopsy. This ability could provide the means to characterise behaviour as well as ecological linkages by facilitating the collection of additional environmental data (e.g. krill biomass, cetacean species community associations, oceanography and ice) over spatial scales that are relevant to blue whale ecology. The collec- tion of such environmental data may yield a more complete ecological characterisation of Antarctic blue whale habitat as has been done for humpback whales in the western Antarctic Peninsula (e.g. Nowacek et al. 2011).

Alternatively, acoustic tracking and targeting of Antarctic blue whales could also be integrated into lower latitude cetacean surveys in austral winter to target vocalising Antarctic blue whales that have migrated north during these months (Stafford et al. 2004, Gavrilov et al. 2012). By using a high spectral resolution when viewing spectrograms of whale calls, the $26 \mathrm{~Hz}$ tone of Unit A is sufficiently distinguishable from vocalisations produced by blue whales around New Zealand (McDonald 2006, Miller et al. 2014), pygmy blue whales in the Indian Ocean (Gavrilov et al. 2011, Gavrilov \& McCauley 2013, Samaran et al. 2013), and those of Chilean blue whales in the southeast Pacific (Buchan et al. 2010, 2014); thus, the risk of misclassification would be minimal.

While the methods and work presented here have focused on blue whales, it is very likely that these, or highly similar methods, could be applied to locate other vocal species of baleen whales. In addition to blue whales, DIFAR systems have already been used for tracking right (McDonald \& Moore 2002, Wade et al. 2006), fin (McDonald \& Fox 1999, Gedamke \& Robinson 2010), and humpback whale calls (Swartz et al. 2003, Garland et al. 2013), and could likely be used to track other baleen whale calls (McDonald 2004), though few of these prior studies acoustically localised whales in real-time. The success of this study, coupled with the decreasing cost and size of computing hardware and ongoing improvements of automated detection and classification software (e.g. Baumgartner \& Mussoline 2011, Helble et al. 2012) further affirms that real-time passive acoustic localisation can greatly improve our capacity to study rare baleen whales. Finally, Peel et al. (2014) provide a freely available simulation framework that could be used to assess the potential improvement in encounter rate offered by this type of passive acoustic tracking.

\section{CONCLUSIONS}

Passive acoustic monitoring was extremely effective at long-range detection of Antarctic blue whales and also in precise guidance of the research vessel for successful achievement of close approaches to Antarctic blue whales, irrespective of weather conditions. By using directional sonobuoys we were able to conduct long-range targeting of whales by following 
the direction of calls using only a single active sonobuoy per listening station. Following bearings to call Unit A eventually led to the detection of ' $\mathrm{D}$ ' and ' $\mathrm{Z}$ ' calls, which, in conjunction with short-range targeting strategies, ultimately led us to groups of Antarctic blue whales (Figs. 2 to 5). The lack of visual sightings of Antarctic blue whales outside of the identified hotspots and the extreme range over which their vocalisations were detected suggests that a high proportion of the groups within a large area would likely be detected with the proposed passive acoustic methods. Hence, we recommend that these methods be considered for future vessel-based studies of Antarctic blue whales.

Acoustic tracking provides for a fundamentally different kind of survey compared to previous designbased visual-line transect sightings surveys such as the SOWER surveys. The ability to monitor and target whales over large areas and long time scales allows Antarctic blue whales to be found efficiently for the purposes of (1) in situ observations of behaviour; (2) genetic sampling and photographic identification for estimates of abundance, distribution, and population structure; (3) estimation of multipliers required for passive acoustic density estimation; and (4) satellite telemetry tagging. Additionally, the ability to acoustically track whales for days at a time should allow for more efficient means to characterise relationships among blue whales, their prey, and the harsh Antarctic environment.

Acknowledgements. The success of the 2013 Antarctic Blue Whale Voyage was due to the support of a large and efficient team, both at sea and at the Australian Antarctic Division headquarters. We thank all the scientists and support staff on the voyage and the operational, shipping and science support provided by the support at the Australian Antarctic Division and Australian Marine Mammal Centre. Thank you to Christopher Donald from Australian Defence for provision of the end-of-life 53D sonobuoys. Particular thanks go to Talley's Group, Gardline Shipping and the excellent and professional crew of the FV 'Amaltal Explorer'. The formative guidance of the International Whaling Commission's Scientific Committee, Southern Ocean Research Partnership, and Antarctic Blue Whale Project group contributed significantly to the success of the voyage. In particular, we thank Natalie Kelly for her guidance and comments throughout the voyage and preparation of this manuscript.

\section{LITERATURE CITED}

Anonymous (2009a) Report of the joint CCAMLR-IWC workshop to review input data for Antarctic marine ecosystem models. J Cetacean Res Manag 11:541-586

Anonymous (2009b) Report of the Seattle SORP Workshop 2009. Submitted to the Scientific Committee of the Inter- national Whaling Commission SC/62/O10:5. Available on request from the Office of the International Whaling Commission (http://iwc.int)

Anonymous (2010) Report of the scientific committee. J Cetacean Res Manag 11:1-98

Barlow J, Taylor BL (2005) Estimates of sperm whale abundance in the northeastern temperate Pacific from a combined acoustic and visual survey. Mar Mamm Sci 21: 429-445

> Baumgartner MF, Mussoline SE (2011) A generalized baleen whale call detection and classification system. J Acoust Soc Am 129:2889-2902

Baumgartner MF, Fratantoni DM, Hurst TP, Brown MW, Cole TVN, Van Parijs SM, Johnson MP (2013) Real-time reporting of baleen whale passive acoustic detections from ocean gliders. J Acoust Soc Am 134:1814-1823

Branch TA (2007) Abundance of Antarctic blue whales south of $60^{\circ} \mathrm{S}$ from three complete circumpolar sets of surveys. J Cetacean Res Manag 9:253-262

> Branch TA, Matsuoka K, Miyashita T (2004) Evidence for increases in Antarctic blue whales based on Bayesian modelling. Mar Mamm Sci 20:726-754

> Branch TA, Stafford KM, Palacios DM, Allison C and others (2007) Past and present distribution, densities and movements of blue whales Balaenoptera musculus in the Southern Hemisphere and northern Indian Ocean. Mammal Rev 37:116-175

> Buchan SJ, Rendell LE, Hucke-Gaete R (2010) Preliminary recordings of blue whale (Balaenoptera musculus) vocalizations in the Gulf of Corcovado, northern Patagonia, Chile. Mar Mamm Sci 26:451-459

Buchan S, Hucke-Gaete R, Rendell L, Stafford K (2014) A new song recorded from blue whales in the Corcovado Gulf, Southern Chile, and an acoustic link to the Eastern Tropical Pacific. Endang Species Res 23:241-252

- Clark CW, Brown MW, Corkeron P (2010) Visual and acoustic surveys for North Atlantic right whales, Eubalaena glacialis, in Cape Cod Bay, Massachusetts, 2001-2005: management implications. Mar Mamm Sci 26:837-854

Cummings W, Thompson PO (1971) Underwater sounds from the blue whale, Balaenoptera musculus. J Acoust Soc Am 50:1193-1198

Double M (2013) Antarctic blue whale voyage 2013: science plan. Australian Antarctic Division, Kingston, TAS. Available at www.marinemammals.gov.au/_data/assets/pdf_ file/0003/141483/ABWV-Science-Plan_FINAL.pdf

Double MC, Barlow J, Miller BS, Olson P and others (2013) Cruise report of the 2013 Antarctic blue whale voyage of the Southern Ocean Research Partnership. Report $\mathrm{SC} 65 \mathrm{a} / \mathrm{SH} / 21$ submitted to the Scientific Committee of the International Whaling Commission. Available on request from the Office of the International Whaling Commission (http://iwc.int)

Ensor P, Komiya H, Olson P, Sekiguchi K, Stafford K (2006) 2005-2006 International Whaling Commission-Southern Ocean Whale and Ecosystem Research (IWC-SOWER) cruise report. Report SC 60(IA1):62 submitted to the Scientific Committee of the International Whaling Commission. Available on request from the Office of the International Whaling Commission (http://iwc.int)

Gales N (2010) Antarctic whale expedition: preliminary science field report and summary. R.V. Tangaroa Feb/Mar 2010. Australian Antarctic Division, Kingston, TAS. Available at www.marinemammals.gov.au/_data/assets/pdf_ file/0016/137302/Gales-2010-Antarctic-Whale-Expedition_ 
Preliminary-field-report-and-summary-Nick-Gales.pdf

Garland EC, Gedamke J, Rekdahl ML, Noad MJ, Garrigue C, Gales N (2013) Humpback whale song on the Southern Ocean feeding grounds: implications for cultural transmission. PLoS ONE 8:e79422

Gavrilov AN, McCauley RD (2013) Acoustic detection and long-term monitoring of pygmy blue whales over the continental slope in southwest Australia. J Acoust Soc Am 134:2505-2513

> Gavrilov AN, McCauley RD, Salgado-Kent C, Tripovich J, Burton CLK (2011) Vocal characteristics of pygmy blue whales and their change over time. J Acoust Soc Am 130: 3651-3660

Gavrilov AN, McCauley RD, Gedamke J (2012) Steady inter and intra-annual decrease in the vocalization frequency of Antarctic blue whales. J Acoust Soc Am 131: 4476-4480

Gedamke J, Robinson SM (2010) Acoustic survey for marine mammal occurrence and distribution off East Antarctica $\left(30-80^{\circ} \mathrm{E}\right)$ in January-February 2006. Deep-Sea Res II 57:968-981

Gedamke J, Gales N, Hildebrand JA, Wiggins S (2007) Seasonal occurrence of low frequency whale vocalisations across eastern Antarctic and southern Australian waters, February 2004 to February 2007. Report SC/59/SH5 submitted to the Scientific Committee of the International Whaling Commission. Available on request from the Office of the International Whaling Commission (http://iwc.int)

Gillespie D, Gordon J, McHugh R, McLaren D and others (2008) PAMGUARD: semiautomated, open source software for real-time acoustic detection and localisation of cetaceans. Proc Inst Acoustics 30(5):54-62

Hall M (2005) Sound propagation through the Antarctic Convergence Zone and comments on three major experiments. In: Proceedings of acoustics 2005. Australian Acoustical Society, Busselton, WA, p 475-479

Hammond P, Barlow J, Charassin JB, Double M, Iniguez M, Walløe L (2013) Antarctic blue whale project overview. Southern Ocean Research Partnership. Available at www.marinemammals.gov.au/_data/assets/pdf_file/0003/ 116355/20130602_ABWP_Project_Overview_Approved .pdf

Helble TA, Ierley GR, D'Spain GL, Roch MA, Hildebrand JA (2012) A generalized power-law detection algorithm for humpback whale vocalizations. J Acoust Soc Am 131: 2682-2699

Klinck H, Mellinger DK, Klinck K, Bogue NM and others (2012) Near-real-time acoustic monitoring of beaked whales and other cetaceans using a Seaglider ${ }^{\mathrm{TM}}$. PLoS ONE 7:e36128

Lavery TJ, Roudnew B, Seymour J, Mitchell JG, Smetacek V, Nicol S (2014) Whales sustain fisheries: blue whales stimulate primary production in the Southern Ocean. Mar Mamm Sci 30:888-904

Matsuoka K, Ensor P, Hakamada T, Shimada H, Nishiwaki S, Kasamatsu F, Kato H (2003) Overview of minke whale sightings surveys conducted on IWC/IDCR and SOWER Antarctic cruises from 1978/79 to 2000/01. J Cetacean Res Manag 5:173-201

McDonald MA (2004) DIFAR hydrophone usage in whale research. Can Acoust 32:155-160

McDonald MA (2006) An acoustic survey of baleen whales off Great Barrier Island, New Zealand. NZ J Mar Freshw Res 40:519-529

McDonald MA, Fox CG (1999) Passive acoustic methods applied to fin whale population density estimation. J Acoust Soc Am 105:2643-2651

McDonald MA, Moore S (2002) Calls recorded from North Pacific right whales (Eubalaena japonica) in the eastern Bering Sea. J Cetacean Res Manag 4:261-266

McDonald MA, Calambokidis J, Teranishi AM, Hildebrand JA (2001) The acoustic calls of blue whales off California with gender data. J Acoust Soc Am 109:1728-1735

McDonald MA, Mesnick SL, Hildebrand JA (2006) Biogeographic characterisation of blue whale song worldwide: using song to identify populations. J Cetacean Res Manag 8:55-65

> McDonald MA, Hildebrand JA, Mesnick S (2009) Worldwide decline in tonal frequencies of blue whale songs. Endang Species Res 9:13-21

Miller BS (2012) Real-time tracking of blue whales using DIFAR sonobuoys. In: McMinn T (ed) Proceedings of acoustics 2012. Australian Acoustical Society, Fremantle, p 7

Miller BS, Kelly N, Double MC, Childerhouse SJ, Laverick S, Gales N (2012) Cruise report on SORP 2012 blue whale voyages: development of acoustic methods. Report submitted to the Scientific Committee of the International Whaling Commission 64/SH11:16. Available on request from the Office of the International Whaling Commission (http://iwc.int)

Miller BS, Barlow J, Calderan S, Collins K and others (2013) Long-range acoustic tracking of Antarctic blue whales. Report submitted to the Scientific Committee of the International Whaling Commission SC/65a/SH1:1-17. Available on request from the Office of the International Whaling Commission (http://iwc.int)

> Miller BS, Collins K, Barlow J, Calderan S and others (2014) Blue whale vocalizations recorded around New Zealand: 1964-2013. J Acoust Soc Am 135:1616-1623

Nardone S, Aidala V (1981) Observability criteria for bearings-only target motion analysis. IEEE Transactions on aerospace and electronic systems, AES 17:162-166

Nowacek DP, Friedlaender AS, Halpin PN, Hazen EL and others (2011) Super-aggregations of krill and humpback whales in Wilhelmina Bay, Antarctic Peninsula. PLoS ONE 6:e19173

Oleson EM, Calambokidis J, Barlow J, Hildebrand JA (2007a) Blue whale visual and acoustic encounter rates in the Southern California Bight. Mar Mamm Sci 23:574-597

> Oleson EM, Calambokidis J, Burgess WC, McDonald MA, LeDuc CA, Hildebrand JA (2007b) Behavioral context of call production by eastern North Pacific blue whales. Mar Ecol Prog Ser 330:269-284

- Payne R, Webb D (1971) Orientation by means of long range acoustic signaling in baleen whales. Ann N Y Acad Sci 188:110-141

> Peel D, Miller BS, Kelly N, Dawson S, Slooten E, Double MC (2014) A simulation study of acoustic-assisted tracking of whales for mark-recapture surveys. PLoS ONE 9:e95602

Rankin S, Ljungblad DK, Clark CW, Kato H (2005) Vocalisations of Antarctic blue whales, Balaenoptera musculus intermedia, recorded during the 2001/2002 and 2002/ 2003 IWC/SOWER circumpolar cruises, Area V, Antarctica. J Cetacean Res Manag 7:13-20

Rone BK, Berchok CL, Crance JL, Clapham PJ (2012) Using air-deployed passive sonobuoys to detect and locate critically endangered North Pacific right whales. Mar Mamm Sci 28:E528-E538

Samaran F, Adam O, Guinet C (2010a) Detection range 
modeling of blue whale calls in southwestern Indian Ocean. Appl Acoust 71:1099-1106

Samaran F, Guinet C, Adam O, Motsch JF, Cansi Y (2010b) Source level estimation of two blue whale subspecies in southwestern Indian Ocean. J Acoust Soc Am 127: 3800-3808

Samaran F, Stafford KM, Branch TA, Gedamke J, Royer JY, Dziak RP, Guinet C (2013) Seasonal and geographic variation of southern blue whale subspecies in the Indian Ocean. PLoS ONE 8:e71561

Širovi A, Hildebrand JA, Wiggins SM (2007) Blue and fin whale call source levels and propagation range in the Southern Ocean. J Acoust Soc Am 122:1208-1215

Širovi A, Hildebrand JA, Wiggins SM, Thiele D (2009) Blue and fin whale acoustic presence around Antarctica during 2003 and 2004. Mar Mamm Sci 25:125-136

Stafford KM, Fox CG, Clark DS (1998) Long-range acoustic detection and localization of blue whale calls in the northeast Pacific Ocean. J Acoust Soc Am 104:3616-3625

Stafford KM, Bohnenstiehl DR, Tolstoy M, Chapp E, Mellinger DK, Moore SE (2004) Antarctic-type blue whale calls recorded at low latitudes in the Indian and eastern Pacific Oceans. Deep-Sea Res I 51:1337-1346

Swartz S, Cole T, McDonald MA, Hildebrand JA and others (2003) Acoustic and visual survey of humpback whale

Editorial responsibility: Robert Harcourt, Sydney, New South Wales, Australia
(Megaptera novaeangliae) distribution in the eastern and southeastern Caribbean Sea. Caribb J Sci 39: 195-208

Thode AM, D'Spain GL, Kuperman WA (2000) Matchedfield processing, geoacoustic inversion, and source signature recovery of blue whale vocalizations. J Acoust Soc Am 107:1286-1300

- Thomas L, Marques T (2012) Passive acoustic monitoring for estimating animal density. Acoustics Today 8:35-44

Urick RJ (1983) Principles of underwater sound, 3rd edn. McGraw-Hill, New York, NY

- Van Parijs S, Clark CW, Sousa-Lima RS, Parks SE and others (2009) Management and research applications of realtime and archival passive acoustic sensors over varying temporal and spatial scales. Mar Ecol Prog Ser 395:21-36

Wade P, Heide-Jørgensen MP, Shelden K, Barlow J and others (2006) Acoustic detection and satellite-tracking leads to discovery of rare concentration of endangered North Pacific right whales. Biol Lett 2:417-419

> Wade P, De Robertis A, Hough K, Booth R and others (2011) Rare detections of North Pacific right whales in the Gulf of Alaska, with observations of their potential prey. Endang Species Res 13:99-109

Wand MP, Jones MC (1995) Kernel smoothing. Chapman \& Hall/CRC, London

Submitted: June 6, 2014; Accepted: August 19, 2014 Proofs received from author(s): October 28, 2014 